\title{
A liberal higher education for all? The massification of higher education and its implications for graduates' participation in civil society
}

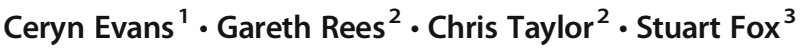 \\ Published online: 13 May 2020 \\ (C) The Author(s) 2020
}

\begin{abstract}
In recent years, questions about the purpose of higher education (HE) have come to the fore as HE tuition fees have escalated both in the UK and internationally. The extent to which universities provide students with opportunities for developing skills needed not only for future employment but participation in civic life has become an important contemporary issue. Drawing on interviews with 29 graduates from three distinct types of UK higher education institutions (HEIs) ('elite,' 'old' and 'new'), the paper explores the extent to which the pedagogical experiences provided by these different institutions offer students the sorts of experiences and skills needed for later civic participation. Our analyses suggest that the pedagogical arrangements in these institutions are highly differentiated and provide varying opportunities for developing civic skills. Whilst this potentially has significant implications for the cultivation of students' civic skills and participation in civil society, we argue that civic participation is not so much determined by pedagogic or disciplinary cultures but is located on the intersection of ranging personal and social circumstances and pedagogic experiences.
\end{abstract}

Keywords Higher education $\cdot$ Graduates $\cdot$ Participation $\cdot$ Social capital $\cdot$ Elite

Ceryn Evans

Ceryn.Evans@swansea.ac.uk

1 School of Education, Swansea University, Singleton Park, Swansea, Wales SA2 APP, UK

2 Wales Institute of Social and Economic Research, Date and Methods (WISERD), 38 Park Place, Cathays Park, Cardiff, Wales CF10 3BB, UK

3 Politics and History Division, Brunel University London, Marie Jahoda Room 221, Hillingdon UB8 $3 \mathrm{PN}, \mathrm{UK}$ 


\section{Introduction}

Universities in the UK have had numerous defining functions over the centuries, from those which emphasised the cultivation of civilisation and the transmission of culture across generations during the Victorian era (Anderson 1992), to more contemporary ideals which have foregrounded the economic contribution of universities to society (Dept for Business, Innovation and Skills 2011). These varying visions reflect profound changes in the structure, size and scale of UK HE. The HE system experienced rapid and substantial rates of expansion in the later decades of the twentieth century (Boliver 2011) and this has led to the increasing diversity of universities and students within the system. Examination of the implications of this for the formation of students' civic skills (such as debating, discussion and critical thinking) and hence their participation in civil society, however, remains scant. This is despite repeated claims that education has a positive role in the development of socially liberal attitudes (such as tolerance for ethnic, cultural and sexual diversity, and an emphasis on individual expression and autonomy) and civic and political participation (Nie et al. 1996; Sondheimer and Green 2010).

In this paper, we examine the role of universities in the cultivation of civic skills. Through the lens of UK graduates' reflections on their university experiences and current civic participation, we explore the extent to which graduates' experiences of university equips them with the sorts of civic skills and knowledge thought necessary for participation in civil society. Civic skills have routinely been conceptualised as those crucial for participation in one's community, such as communication, team-working, organisational, research skills and grassroots activism and community volunteering (Brady et al. 1995; Rosenstone and Hansen 1993). They also include critical thinking, reflection, debating, discussion and analytical skills, and cognitive and verbal abilities (Verba et al. 1995). The role of education in fostering these skills has received the attention of social and political scientists. Nussbaum's $(1997,2010)$ discussion about the need for the inclusion of arts and humanities in undergraduate education is particularly significant here. For Nussbaum (2010), the arts and humanities are associated with the cultivation of, not only reasoning, logical and critical thinking skills but also emotions such as empathy, compassion and understanding of others' perspectives. Such skills and ways of thinking are essential for democracy and humanity more generally, as they enable thoughtful participation in democratic life through critical reflection on one's own and others' perspectives. Whilst she makes her case with respect to liberal arts higher education in America, her arguments resonate with debates in the UK and elsewhere about HE's wider purpose and its role within civil society.

In casting our attention to the role of the university in the development of these kinds of skills, we cannot, however, ignore the ways in which an individual's intentions and capacity to participate in civic life are informed by a myriad of social, personal and geographical circumstances. Civic participation is at once socially structured, informed by the resources (time, money, skills) and constraints that enable and curtail participation (Schlozman et al. 1999; Dean 2015). It is also shaped by the availability of actual (or objective) opportunities to participate. Also, important here are individuals' choices, preferences, motivations and interpretations of their opportunities for participation. This latter 'subjective' dimension of opportunity (Hodkinson and Sparkes 1997) may also have a social underpinning in the sense that early childhood experiences orientate people towards participation in particular ways. Bourdieu's (1986) concept of habitus is useful for considering how an individual's location within the social structure might dispose them to particular ways of thinking, feeling and 
behaving in relation to civic participation (Dean 2015). For Bourdieu, the habitus is an enduring set of dispositions acquired through socialisation which orientates individuals' responses to social situations (Bourdieu 1986). Since the habitus is the embodiment of one's location in the social structure, people's behaviours and actions in relation to civic participation are in part socially structured (Dean 2015). This is not to say that their behaviours will be determined by their childhood experiences, yet the choices they make will be set within the boundaries of their objective and subjective opportunities (Hodkinson and Sparkes 1997), the parameters of which are externally constructed. What we hope to explore here is the intersections of these objective and subjective dimensions of opportunities and institutional and disciplinary cultures in people's civic participation.

\section{The massification of higher education}

The UK HE system has expanded substantially throughout the second half of the twentieth century (Boliver 2011), transforming from an 'elite' system characterised by roughly 4-5\% enrolment rate of school leavers to a 'mass' system enrolling between 30 and 50\% (Trow 2005; Anderson 2006). One of the most profound effects has been the diversification of the university sector itself (Trow 2005; Telling 2018). New institutions have been incorporated into the university sector and institutions which once resided within the public HE sector, including polytechnics and colleges, became universities following the dismantling of the binary divide in 1992 (Boliver 2011). The resulting institutional diversity has increased the range and scope of subject disciplines and forms of pedagogical experience made available to students. This institutional diversity, along with decades of UK governments' agendas for widening participation in HE (Dearing 1997; DfES 2003), has helped diversify the student body as more students have entered HE from a range of social, cultural and ethnic backgrounds (Morgan 2013).

But the distinction between elite and mass HE is not only reflected in the expansion of student numbers and the diversification of institutions and student body. The massification of $\mathrm{HE}$ has been accompanied by changes in both its conceptualisation and the purpose of $\mathrm{HE}$ envisioned in policy and society more widely. The Robbins Report (Robbins 1963) not only emphasised the role of HE in the 'general division of labour' through the instruction of skill but it also emphatically echoed nineteenth-century sentiments regarding the civic purpose of university education. Robbins emphasised the transmission of a common culture and 'common standards of citizenship' as a key role of HE, arguing that universities and colleges have an important role to play in the 'general cultural life of the communities in which they are situated' (Robbins 1963). By the 1990s reference to HE's civic contribution was almost absent in HE policy, replaced by a narrative of economic competitiveness. The Dearing Report (1997)) made several minor references to the envisaged purpose of HE advocated in the policy up until the Robbins Report (such as the importance of HE for cultivating the kinds of skills needed for a democratic society such as critical thinking, analysis and rational argument and in cultivating 'a willingness to debate issues rationally and openly' amongst students (Dearing 1997, p. 80)). However, these were vastly overshadowed by a preoccupation with the role of $\mathrm{HE}$ in the competitive economic success of the nation. This emphasis has continued to be a central pillar of HE policy-making in England and Wales ever since (DfES 2003; Welsh Assembly Government 2009; Dept for Business, Innovation and Skills 2011). The contemporary emphasis on the economic benefits of HE (for individuals and society) is coherent with funding arrangements which have placed increasing onus on the individual to fund the cost of HE. 
Yet to imply that there is a sharp conceptual boundary between elite and mass HE is not an accurate representation. As Trow (2005) argued, the distinction between the aims of elite HE (aligned with a more general 'liberal' education) and those of mass HE (associated with vocational and technical education) has become blurred as the sector has massified. To be sure, Trow regards elite $\mathrm{HE}$ as having a more general purpose in which the cultivation of the citizen for a variety of leadership roles was central, rather than training for 'specific job roles' (Trow 2005 , p. 9). This contrasts with the shift to a massified system characterised by a move towards more technical and vocational education and training. However, forms of elite HE including the emphasis on liberal education, the 'shaping of mind and character' and more general socialisation (Trow 2005) and pedagogic practices can still be found within elite institutions in a mass HE system. By the same measure, new universities which have entered the university sector with the massification of HE (which are routinely known as post-92 universities) offer programmes (such as degrees in Philosophy and Classics) and have adopted pedagogic relations between student and tutor (such as tutorials) which are similar to those present in universities which have typified traditional elite HE such as Oxford and Cambridge (Trow 2005). In other words, whilst we have witnessed the massification of HE, the practices, intentions and purposes associated with elite HE have remained within a mass HE system, and ideas which characterise the purpose of mass HE have found their way into elite institutions (Trow 2005). Such conceptual blurring therefore raises questions regarding the extent to which the relics of elite HE continue to exist and in turn bear on students' civic skills and subsequently their future civic behaviours. Such questions are important for deepening understanding of the role of HE in the socially uneven distribution of social capital (Bourdieu 1986, Putnam 2000).

Defining precisely what is meant by civic participation is challenging because the concept is contested. This is particularly the case regarding whether it includes activities that are explicitly political (such as voting) and whether it is limited to activities intended to improve one's community, and how much contact and interaction with other members of that community it implies (Adler and Goggin 2005; Fox 2014; Gaby 2017). There are also disagreements about the necessity for civic participation to occur within an institutional setting (such as through membership of a local church), and/or whether the benefits attributed to it are more likely to result from institutionalised activities (Putnam 2000; Adler and Goggin 2005). Most definitions agree, however, that civic participation refers to voluntary, community activities occurring beyond the home and workplace, and imply some form of involvement with the people, institutions or issues of that community. They also agree that such activities can produce both communal and individual benefits, such as improved social capital, health, employment prospects, political representation and life satisfaction, linking inequalities and/ or changes in experiences that facilitate civic participation with inequalities and/or changes in socio-economic status, health and political influence (Adler and Goggin 2005; Putnam 2000; Verba et al. 1995). In this research, we do not attempt to limit the definition of 'non-political' acts, as the distinction between 'political' and 'non-political' civic acts is blurry at best. In addition, often in practice, it refers to acts that occur within the institutionalised/electoral political arena and those that do not, an increasingly problematic means of identifying 'political' and 'non-political' at a time when non-electoral political activity is becoming increasingly common (Fox 2014). We also focus predominantly on institutional civic activities because it provides a greater degree of conceptual clarity when inviting people to discuss their civic behaviour and makes comparisons in people's accounts of that behaviour easier to maintain. If universities in a massified system are differentiated in the extent that they provide 
particular pedagogic experiences for students which ultimately foster civic skills needed for future civic participation (debating, discussion and critical thinking) (Verba et al. 1995), this may be an important mechanism in the reproduction of the socially uneven distribution of social capital and social inequalities more widely.

\section{The study}

We draw upon the findings of an ESRC-funded project (ES/L009099/1, April 2015-March 2017) which explored the implications of the massification of HE for civil society in the UK. To capture the diversity of institutional types within a massified HE system, we interviewed 29 graduates who had attended one of three distinct types of HEI in the UK; these were 'elite' institutions (which included the Universities of Oxford and Cambridge ${ }^{1}$ ), 'old' (which, in this sample, were graduates from a single Russell Group ${ }^{2}$ university) and 'new' (which included graduates from two post- 92 universities $^{3}$, (i.e. those that were once Polytechnics or institutes of HE prior to 1992). These universities were selected because they enabled us to capture institutional diversity ${ }^{4}$ and differences in their associations with elite and mass HE, with the 'elite' and 'old' universities having features which more closely resemble the purposes of elite HE systems than the new universities. These distinctions are further reflected in the pedagogical relationships which characterise these institutions. The universities of Oxford and Cambridge have the kinds of features Trow describes as being characteristic of elite higher education. These include particular kinds of relationships between learners and tutors such as 'close and prolonged' pedagogical relationships (Trow 2005).

We borrow Trow's (2005) conception of liberal education which he regards as being associated with elite higher education which emphasises the transmission of culture and is characterised by particular pedagogic relationships between students and teachers. We also draw on Nussbaum's $(1997,2010)$ arguments about liberal arts higher education in which she emphasises the importance of particular disciplinary cultures such as the humanities and arts for the cultivation of particular skills and ways of thinking (including criticality, deliberation, reasoning and debate). In this sense then, we use the term liberal (higher) education to refer not only to forms of curriculum and pedagogy, as referred to by Nussbaum (1997, 2010), but to ideas about the purpose and function of higher education in civil society as discussed by Trow (2005). Our attention to graduates who had studied different degrees at different universities aimed to capture these dimensions of liberal higher education in which both the pedagogic and curriculum features, as well as more broadly defined purposes, are brought to the fore.

Qualitative semi-structured interviews, with a biographical focus, were conducted with 11 Oxford and Cambridge graduates, 10 Russell Group university graduates and eight graduates from two post-92 universities. All were aged 30-40 and had participated in a 'mass' HE system between the period 1996 and 2007, yet those who graduated from the universities of

\footnotetext{
${ }^{1}$ The universities of Oxford and Cambridge have been named because we wanted to draw attention to their distinct pedagogic features. Any attempt to conceal the names of these institutions would undermine the richness and integrity of the data.

2 The Russell Group is a group of 24, world-class research-intensive universities in the UK.

3 'New' universities are institutions which became universities after the passing of the Further and Higher Education Act of 1992 (hence 'new' or post-92 universities).

${ }^{4}$ Though we would have liked the graduates from the 'new' institutional type to have graduated from a single institution, given the difficulties we faced in recruiting sufficient numbers of graduates from one institution, this meant that it was necessary to recruit from more than one institution.
} 
Oxford and Cambridge could be said to have participated in 'elite' institutions within the mass system. The graduates had studied a range of degree disciplines; there were 16 arts and humanities or social sciences graduates (AHSS), nine STEM (science, technology, engineering, mathematics) graduates, two business studies graduates and two social and healthcare graduates. In total, 20 were female and nine were male. All were employed and overwhelmingly held professional or semi-professional employment with 17 also holding post-graduate qualifications (typically Master's and $\mathrm{PhDs}$ ). The graduates overwhelmingly lived in Wales (24), three lived in England and two were living outside the UK. Based on their parents' occupations, nine came from backgrounds that could be described as working-class and 20 were from more middle-class backgrounds.

The participants were recruited through snowball sampling whereby the researchers initially used their contacts with graduates to accumulate individuals through these contacts' friends, colleagues and acquaintances. Sampling 'bias' is undoubtedly a potential problem of this method given that graduates were in some way socially connected (albeit tentatively in many cases) to each other and therefore might have had common experiences and social and demographic situations. Nonetheless, such an approach enabled the recruitment of graduates from across a range of universities effectively and efficiently and was invaluable for recruiting individuals who were geographically dispersed.

The interviews explored a range of themes including participants' university experiences and their current civic participation. Graduates were asked to reflect on their academic experiences (the degree subject they had studied and the content of the curriculum, as well as the pedagogical experiences they had whilst at university, i.e. whether they were taught through seminars, tutorials or lectures and the nature of relationships with tutors, etc.). They were asked to discuss their current patterns of participation in social affairs, including their involvement in community organisations, religious or political participation, voluntary groups, charities and sports, as well as their social and political values, voting patterns and political allegiances.

Most interviews were conducted face to face, either in participants' homes or in the offices of the researchers. Six were conducted either over the phone or via Skype where graduates lived geographically distant from the researchers. Interviews were recorded using a digital voice recorder and the audio files were transcribed using a professional transcription company. The data on which this paper rests comes from interviews with individuals who graduated from university at least 15 years previous, and in some cases up to 20 years. In drawing conclusions from this study, we are mindful, therefore, of the need to reflect critically on these accounts and to recognise that they are re-constructions of their experiences. This does not mean that they are in any way less 'valid' yet we wish to emphasise that these re-constructions should not be conflated with their experiences and maybe quite different if they had been gathered at a different time point.

The analysis was guided by a conceptual framework which emphasised the role of universities in the cultivation of civic behaviours and values. In particular, we drew on Trow's (2005) conceptualisations of the distinctions between elite and mass HE to explore the extent to which features of elite HE exist within a massified system and the significance of this for graduates' civic attitudes and behaviours. Hence, Oxford and Cambridge could be regarded as fully resembling the 'elite' ideal type, post-1992 approximating to the 'mass' ideal type, with the Russell Group somewhere in between in terms of the nature of their pedagogical characteristics and social environments. An important aspect of this analysis was drawing out the complexity of relationships between pre-university experiences, personal and social 
circumstances and university experiences. To support our analysis here, we have made use of Bourdieu's (1986) concept of habitus and Hodkinson and Sparkes' (1997) notion of subjective and objective opportunities to consider how people's opportunities for civic participation are routinely framed by wider social contexts. Thematic analysis was used, with comparisons made between data from interviews conducted with graduates from the three different types of institution. This enabled examination of the extent to which participation in a particular institution, with distinct pedagogic environments, had a bearing on the formation of civic skills and graduates' later civic participation. For this reason, quotes were identified which exemplified emergent themes within the data, particularly where they highlighted points of comparison between graduates across different institutions.

\section{Graduates' civic participation: pedagogic experiences and the formation of civic skills}

The graduates were hugely varied in terms of their civic participation; some took part in multiple activities and engaged in them regularly, whilst others took part either in very few or no formally organised activities. Amongst those who did participate, the activities they participated in included charities, Parents' and Teachers' Associations (PTA), scouts and guides associations, trade unions and political parties. Their participation ranged from simple membership to more active participation, including acting as treasurer, chair, secretary or board member for associations or organisations, taking part in informal helping in their local communities such as helping out at children or school groups or club through offering their time or resources.

AHSS graduates were far more civically active than STEM graduates, meaning they took part in more activities and the nature of their engagement was more 'intense' requiring significant amounts of their time. Eleven out of the 16 AHSS graduates were active in at least one associational organisation, compared with five out of 13 STEM, Business or Health and Social graduates. However, the AHSS graduates were not homogenous in this respect; there were subtle yet important distinctions amongst them which, in part, may reflect variations in their pedagogic experiences. Whilst there was little numerical difference between the AHSS graduates in how frequently they alluded to the role of their pedagogical experiences in developing civic skills or attitudes, the Oxford and Cambridge graduates' narratives were more striking in this respect. They placed a stronger emphasis on the role of pedagogy in informing their civic skills than the AHSS graduates from the other universities. For example, Simon, an AHSS Oxbridge ${ }^{5}$ graduate, reflected on how he was encouraged to debate, discuss and critically engage during his undergraduate study:

I remember once in a tutorial, two of us and a tutor and I asked the tutor a question, can't remember what it was about but I asked her a question... and she said, "I don't know but I suspect you have a theory". And that was... how it is, sort of test theories and suggest things and defend an argument you've made in your essay... (Simon, AHSS, Oxbridge).

Carys, an Oxbridge AHSS graduate, similarly emphasised how she'd learnt arguing and analytic skills:

\footnotetext{
${ }^{5}$ Whilst we recognise that the term 'Oxbridge' understates the distinctions between the universities of Oxford and Cambridge, it was felt that this term should be applied when discussing the data in order to protect the confidentiality of the participants.
} 
I mean you were encouraged to debate, we had seminars as well and we were encouraged to kind of...challenge each other and there was something about, learning from other people, like how they saw things... I mean it was good in the sense that it taught me how to analyse literature in a more advanced way than I'd been able to do previously, and I suppose look at things in different ways and consider different perspectives on things and develop argumentative, argument styles and things like that (Carys, AHSS, Oxbridge ).

Both Simon and Carys's excerpts bring to mind Trow's (2005) conceptualisation of elite HE, characterised by 'relatively close and prolonged relationship between student and teacher' (Trow 2005, p. 11). The pedagogic environment of Oxford boasts a highly distinctive pedagogical practice in the form of its tutorial system. The tutorial typically involves one or two students meeting with a tutor who is usually an expert in her/his subject area, once or twice a week. The tutor provides feedback on the student's written work, casting the tutorial as a space for in-depth discussion, debate and analysis of an issue or topic (Ashwin 2005). A similar pedagogical arrangement is present in the Cambridge 'supervision' system, where students typically receive feedback from an expert on a piece of their written work, discuss ideas and debate a topic or issue. The 'Oxbridge tutorial', as it is referred to by Ashwin (2005), has been described as a space for intellectual development and independent thinking. Crucially, according to Moore (1968), it is a space in which knowledge is seen as contested and in which critical thinking and analysis is fundamental. Typically, the student is encouraged to posit their own critical analysis of an idea or problem to the point where they gradually acquire intellectual independence from their tutor (Moore 1968). Ellen's (an AHSS graduate from Oxbridge) quote echoes Moore's conceptualisation of the Oxbridge tutorial as a space for the development of independent critical thinking and analysis:

Yeah, so you might write something about, I don't know like Descartes Proof of God and you might say, 'oh, well I don't think there is a God because of this' ....and then the lecturer would usually sort of play the Devil's advocate and say 'well I think there is a God because of this' and sort of the three of you then would try and sort of unpack that and get to a point where we all had a stand point and could justify it (Ellen, AHSS Oxbridge).

Whilst Moore's (1968) conception of the 'tutorial' is somewhat idealised and contested (Ashwin 2005), it is nonetheless echoed in the narratives of the Oxford and Cambridge AHSS graduates in this research. In these narratives, we find that the tutorial is always doing two things simultaneously, at once teaching/imparting subject knowledge whilst also nurturing distinctive social and civic skills including critical thinking and analytical skills. In this sense then, the pedagogic environment associated with particular (elite) institutions appears to have a role in fostering civic skills. Whilst the AHSS graduates at the Russell Group and post-92 universities also occasionally reflected on the way in which they had the opportunity to gain experience of intense, close and prolonged tutor-student pedagogical relationships, reference to this mode of learning was much more limited. AHSS graduates from the post-92 institutions had routinely experienced pedagogic relationships in which skills were transmitted through a brief and impersonal tutor-student relationships offering a limited opportunity for the kinds of 'close and prolonged relationship between student and teacher' to develop (Trow 2005, p. 11).

What's more, where AHSS graduates from the Russell Group university alluded to the way in which their university experiences had provided them with opportunities to develop civic 
skills (such as debating and discussion skills) they tended to do so whilst referring to their degree discipline specifically, rather than the pedagogic environment per se. Three of the four AHSS graduates from the Russell Group did this, including Ben, who reflects:

I think it [referring to AHSS degree], has definitely made me more, I suppose, aware and kind of critical if you like... because I suppose, recently one thing that I think has changed me in the last couple of years is my engagement with kind of political debate and things like that, which prior to University certainly was something I never really engaged with much, and even during my under grad, I probably don't think I did that much either. Um, but I think having done a degree in [AHSS] and things like that has, kind of gave me the, the awareness but also the, the interest and the ability to kind of engage ... (Ben, AHSS, Russell Group).

It seems, therefore, that for some students, it is the coupling of AHSS degrees with the pedagogic environments of particular HEIs (such as those characterised by the tutorial systems of Oxford and Cambridge) which explicitly intend to cultivate skills in debate, discussion and critical thinking that the generation of civic skills is most supported. The extent to which these skills are ultimately utilised in later civic participation is a moot point. Nevertheless, it was striking that 6 out of 9 of the AHSS graduates from Oxford and Cambridge participated in civil society in a range of ways, including holding memberships of political parties, volunteering in community organisations or charities and taking part in demonstrations. This may suggest that particular disciplines such as arts, humanities and social sciences seem to be especially important in fostering civic skills when they are delivered in the context of particular pedagogic environments. The significance of this coupling of disciplinary culture with the pedagogic environment of the HEI more generally is reflected in the narratives of STEM graduates from the universities of Oxford and Cambridge. These graduates tended not to view their degree (neither the curriculum nor their pedagogic experiences) as providing them with opportunities for debate and discussion, but rather in transmitting specific vocational and academic skills and knowledge. Trow's (2005) assertion that the sharp distinction between elite and mass higher education no longer holds is brought to mind here; features typical of mass higher education (including the transmission of skills and knowledge designed for vocational preparation) exist in more traditional elite institutions such as Oxford and Cambridge within a mass HE system. Thus, despite these STEM graduates having attended elite higher education institutions which according to Trow (2005) have pedagogic features such as close and prolonged student-teacher relationship, the degree discipline they undertook did not appear to help foster civic skills, perhaps because it did not engage them in the kinds of debate, discussion and critical thinking which is characteristic of humanities, arts and social science subjects. Nadia, a STEM graduate from Oxbridge, alludes to this when asked if there was any space for debate and discussion during her degree:

To be honest, the way I remember it was 'what problems have you got in the question papers and let's work through the problems in the question papers'. So it was very much about the academic understanding and application of being taught. I think that's what I missed, it wasn't a big wide discussion (Nadia, STEM, Oxbridge).

If the translation of civic skills into civic participation were straightforward, then we might expect homogeneity amongst our AHSS graduates from Oxford and Cambridge in the intensity of their civic participation. Yet, this was not the case. A minority of our AHSS graduates from these universities (three out of nine) were not at all or only minimally 'active'. 
Civic participation is not simply informed by university experiences, but rather, it is shaped in a relationship between pedagogic and curriculum experiences, a range of social and personal circumstances and pre-university experiences which are socially and spatially structured. In the following, we discuss some of these personal, social and geographical contexts which frame civic participation.

\section{Personal, social and geographical contexts and civic participation}

Students enter university from socio-economic and geographic contexts which inform the development of civic skills, their social and political attitudes and values and orientations towards civic participation (McIntosh et al. 2007). The family provides an important context for the development of civic skills such as debate and discussion, civic knowledge and social and political values (Beck and Jennings 1991; McIntosh et al. 2007). All the graduates reflected on their exposure to social and political ideas and values (usually from their parents), prior to entering university. Yet amongst our graduates, it was those from middle-class backgrounds who spoke most intensely about their exposure to their own parents' participation when they were growing up and commented that this had played a part in shaping their own views, values and orientations towards civic participation. Twelve out of 20 graduates from middle-class backgrounds spoke of at least one parent being civically active. By contrast, seven out of the nine graduates from working-class backgrounds said their parents participated in very few activities when they were growing up. Caitlyn, an Oxbridge graduate from a middle-class background, discussed how her own current participation in social and political activities may have been informed by her parents' values and civic participation. At the time of the interview, she volunteered in community organisations, took part in political demonstrations and was a member of a trade union. She commented;

So he [father] was a trade union rep and he was very active in that sort of thing, in that sort of world. So I was aware of that growing up and that's had a big influence on me in my current life I suppose and as an adult growing up (Caitlyn, AHSS, Oxbridge).

Caitlyn's experiences of witnessing her parents' involvement in civic activities as a child may have helped generate a 'structure of presuppositions' (Rees et al. 1997) which guided her own thinking and feeling about participation. If social capital (and hence civic participation) is in part socially structured (Verba et al. 1995; Dean 2015), this must be accounted for when considering the intensity of our AHSS graduates' civic participation. AHSS graduates were overwhelming from middle-class backgrounds (11 out of 16 had parents with professional or managerial occupations and had themselves participated in higher education). Their own current participation may at least partly reflect their childhood experiences of their parents' participation which may have orientated their thinking and behaviours in relation to it.

But classed dimensions of participation are not only present in family discussions around participation but are also located geographically. Whilst Ellen reflected on the ways in which her university course had provided her with opportunities to develop skills in critical thinking, debate and discussion (above), her formative experiences (including growing up in a workingclass community in South Wales, characterised by a strong political identity) are likely to have played a role in the cultivation of her own social and political values and hence civic 
participation (at the time of interview Ellen was a member of the Labour Party and volunteered for a mental health charity):

Well we just, I mean we just grew up in an incredibly left wing, it wasn't even a broad left wing, it was a very specific Labour Party community... so yeah it's just a very strong Labour tradition in Pen-y-Bae and I think I continued that in the sense of, maybe it was sort of an inertia of not really seeing anything else which I thought was a better alternative (Ellen, AHSS, Oxbridge).

Ellen's quote exemplifies a subtle but important theme present in the interviews. This was defined by graduates' references to the geographic location in which they were brought up and its role in orientating them towards particular political perspectives or parties. Angharad, a STEM graduate from the Russell Group university who was brought up in a location with a strong Plaid Cymru 'identity', also reflects on the role that location played in her developing political views:

And it's probably the area I'm from as well, but no, we've always been down the line in my family, we've been big Plaid members... So I feel quite strongly that we should have our say and that we're not the same and ... to be kind of governed by a government who barely knows you exist is ... something that makes me feel quite strongly towards Plaid Cymru (Angharad, STEM, Russell Group).

Whilst Angharad was emphatic in her support for Plaid Cymru, her participation in political activities (other than voting) was limited. It is here that we witness the interaction of a range of social, geographical, personal circumstances and pedagogic experiences in shaping civic participation. Whilst both women grew up in places characterised by strong political identities (Labour for Ellen and Plaid for Angharad), the patterns of their participation were distinct. Though Angharad's pre-university experiences may have primed her political values and orientated her towards particular political parties, she did not experience the kinds of pedagogic environment that Ellen had (i.e. the AHSS degree which she undertook) which appears to have helped develop skills for civic participation in later life.

Yet participation is not only informed by individuals' early (classed and geographic) experiences of participation, which frames their orientations towards participation, it is also informed by their actual opportunities to participate. As Schlozman et al. (1999) explain, people's capacity to participate will be informed by the availability of their resources (including time, skills and money). The presence of resources may mediate the relationship between civic skill formation and participation and may help to explain why a small number (three out of nine) of AHSS graduates from Oxford or Cambridge civic participation was minimal, despite experiencing 'elite' pedagogic environments as well as types of curriculum that are crucial for cultivating civic skills. Tanya was an AHSS student from Oxbridge whose pedagogic experiences at university may have helped foster the skills needed for civic participation. However, her subjective opportunities for civic participation was significantly curtailed by her current social and personal circumstances, including her perceptions of her limited time:

I don't really do very much I don't think. I've got a nearly four year old daughter so that takes up quite a lot of spare time...I don't think I've sought those out because I've been busy working and having a child (Tanya, AHSS, Oxbridge).

\footnotetext{
${ }^{6}$ Plaid (or Plaid Cymru) is a socio-democratic political party in Wales advocating Welsh independence.
} 
Similarly, Laura, an AHSS student from Oxbridge, reflected on her current spare time activities being considerably curtailed by having young children. When asked about her participation in civic activities, she replied:

Now, not much I've got two children ...Yeah and a third one that's about to arrive (Laura, AHSS, Oxbridge).

The importance of graduates' current social and personal circumstances, as well as personal preferences and motivations in their civic participation, cannot be emphasised enough. These play an important role in mediating the translation of civic skills into civic participation. For some graduates, having young families seriously curtailed their opportunities to participate (like Tanya and Laura) whilst for others, it opened up their opportunities. This suggests that opportunities for civic participation are simultaneously objective and subjective; they are defined by the scope of available opportunities as well as individuals' interpretations of them. These personal, social and geographical contexts also help to explain the civic participation of some of our AHSS graduates who were not at elite universities. Megan was an AHSS graduate from a post-92 university and was heavily involved in volunteering activities associated with her young children (she volunteered on a breastfeeding support group and took part in volunteering activities at her children's nursery). Whilst the pedagogic experiences she had at university did not, in her view, provide space for the development of civic skills, her adulthood participation was enabled by a range of personal, social (including gender and social class) and life-course contexts:

We've always had a very local community. We have you know, I think a lot of workingclass communities have very sort of local, they are very close-knit communities anyway. And I think those are the reasons I volunteer and why I'm involved in the [nursery] rather than anything to do with going to university. You know the nursery is a local nursery that we are all supporting. The, you know the breastfeeding support work is for women who live within that local community (Megan, AHSS, Post-92).

In Tanya, Laura and Megan's excerpts, we witness how nuanced personal and social circumstances mediate the role of their pedagogic experiences in informing their civic participation. Whilst all three women had graduated with AHSS degrees, which have been described as key discursive environments for the development of civic skills (Nussbaum 1997, 2010), the intensity and nature of their participation were vastly different. Tanya and Laura came from middle-class homes and both of them embarked on AHSS degrees at Oxford/Cambridge, where the disciplinary and pedagogic environment is arguably most conducive to civic skill formation (Nussbaum 2010). Yet, their participation was minimal, curtailed by their objective and subjective opportunities to participate (including their perceptions of the availability of time). By contrast, Megan's commitment to volunteering in her local community emerged from circumstances relating to her working-class identity, gender, having children and her subjective interpretations of opportunities for volunteering. Thus, whilst some pedagogic experiences may provide an important context for the development of civic skills unless both objective and subjective opportunities for participation are available, the translation of civic skills into active participation may be stifled.

\section{Conclusions}

The transition from elite to mass HE has been paralleled by profound changes in the way in which HE is conceived and its purposes defined in the policy. The question we asked was, 
what does this mean for the cultivation of civic skills and participation in civic associations amongst graduates emerging from different types of institutions within a mass HE system?

The pedagogical experiences of these graduates were highly diverse and mapped onto the ideal type of elite HE to different degrees. Forms of pedagogic relationships which are characteristic of traditional elite HE are very much present within a massified system, largely in the universities of Oxford and Cambridge. When the pedagogic practices featuring distinct kinds of tutorial and supervisory systems characteristic of these institutions are combined with forms of curriculum associated with a liberal arts education as described by Nussbaum (2010) including the arts, humanities and social sciences, they facilitate the cultivation of distinctive skills required for many forms of civic and political participation. For students who have had limited opportunities to develop such skills prior to entering university, then the university potentially provides an important space for such development. Going to university and studying particular subjects may therefore have a crucial role in the accrual of social capital, a resource which brings benefits for the individual and collective (Putman 2001; Coleman 1988; Bourdieu 1986).

But civic participation does not simply emerge from the pedagogic experiences an individual has at university. It is set in a relationship between a range of personal, social, geographic circumstances (gender, employment situation, having children) and pedagogic experiences, as well as pre-university experiences. All of these contexts define the scope of individuals' objective and subjective opportunities to participate. This subjective dimension of opportunity may, to some extent, be socially structured in the sense that early childhood experiences orientate people's thoughts and feelings towards participation, as Bourdieu's (1986) concept of habitus would suggest. Individuals' location within wider social and spatial contexts, prior to them embarking on the university, appears to prime their social and political views and structure their preferences (Rees et al. 1997) in relation to participation. But people's capacity to participate will also be informed by their objective opportunities to participate which are shaped by their availability of resources (money and time). This means that for some individuals, despite engaging in particular degree courses at university (such as AHSS courses) and having had particular pedagogic experiences, such as those characteristics of the tutorial and supervisory of the universities of Oxford and Cambridge, the civic skills fostered through these experiences may not be translated into civic participation if objective opportunities are not available or people do not perceive them to be. As we discussed, some of our graduates experienced pedagogic environments which help to cultivate civic skills but were not, at the time of the interview, highly civically active.

Nevertheless, if the pedagogic environment of some universities and degree courses help foster civic skills, their potential role in the reproduction of social capital cannot be ignored. If these are precisely the skills required for civic participation, which in turn bestows advantages in a range of social and political spaces (Verba et al. 1995), then some students will continue to have greater experiences and opportunities for acquiring skills, knowledge and attributes depending on the universities they attend, the subjects they study and a range of social and personal contexts that make participation possible. HE has long been identified as a key player in the reproduction of social inequalities through the association of different degree qualifications and universities with more or less lucrative financial rewards (Chevalier and Conlon 2003). Crucial as this issue is, the contemporary overwhelming focus on the economic outcomes of graduates within a massified HE system has meant that the role of HE in the production and reproduction of alternative markers of inequality, including social capital, has been relatively unexplored. Given that the pedagogic practices and environs of the universities 
of Oxford and Cambridge continue to provide a type of liberal education which is deeply privileging through the way it bestows graduates with skills for civic participation, we might argue that the transition from elite to mass HE has done little to affect the role of HE in the reproduction of inequalities in social capital. If politicians and senior university personnel are to create more equitable $\mathrm{HE}$ experiences and outcomes for graduates from all backgrounds, then it is imperative that they also consider how all universities could be better supported in developing the skills and attributes that foster graduates' participation in both the economic and civic spheres of life within and after university.

Whilst we have cast our lens on higher education in the UK, the implications of our findings for universities, graduates and HE policy-makers across the globe are significant. At a time when the arts and humanities (and to some extent the social sciences) are receiving considerable funding cuts internationally due to their perceived lack of economic benefits, it is essential that we continue to highlight the centrality of these subjects in fostering the kinds of skills that are essential for the healthy functioning of democracy (Nussbaum 2010). Whilst we do not intend to conclude that particular pedagogic and curricular environments cause civic participation, they are nevertheless crucial disciplinary spaces for the development of civic skills and ways of thinking about society. Echoing Nussbaum's (2010) contentions here, overlooking this could have significant and perilous implications for the functioning of civil society and the cultivation of humanity more generally.

Acknowledgements We would like to thank the anonymous reviewers for their highly instructive comments and suggestions on earlier drafts of this paper.

Open Access This article is licensed under a Creative Commons Attribution 4.0 International License, which permits use, sharing, adaptation, distribution and reproduction in any medium or format, as long as you give appropriate credit to the original author(s) and the source, provide a link to the Creative Commons licence, and indicate if changes were made. The images or other third party material in this article are included in the article's Creative Commons licence, unless indicated otherwise in a credit line to the material. If material is not included in the article's Creative Commons licence and your intended use is not permitted by statutory regulation or exceeds the permitted use, you will need to obtain permission directly from the copyright holder. To view a copy of this licence, visit http://creativecommons.org/licenses/by/4.0/.

\section{References}

Adler, R. P., \& Goggin, J. (2005). What do we mean by 'civic engagement'? Journal of Transformative Education, 3(3), 236-253.

Anderson, R. (1992). Universities and elite in Britain since 1800. Cambridge: Cambridge University Press.

Anderson, R. (2006). British Universities Past and Present. London: Hambledon continuum.

Ashwin, P. (2005). Variation in students' experiences of the 'Oxford. Tutorial' Higher Education., 50(4), 631644.

Beck, P. A., \& Jennings, M. K. (1991). Family traditions, political periods and the development of partisan orientations. The Journal of Politics, 53(3), 742-763.

Boliver, V. (2011). Expansion, differentiation and the persistence of social class inequalities in British higher education. Higher Education, 61(3), 229-242.

Bourdieu, P. (1986). The forms of capital. In J. G. Richardson (Ed.), Handbook of theory and research for the sociology of education (pp. 241-258). New York: Greenwood.

Brady, H. E., et al. (1995). Beyond SES: A resource model of political participation. American Political Science Review, 89(02), 271-294.

Chevalier, A. N. and Conlon, G.. (2003). Does it pay to Attend a Prestigious University? London, Centre for the Economics of Education: LSE. 
Coleman J. S. (1988). Social capital in the creation of human capital. American Journal of Sociology. 94, S95121

Dean, J. (2015). Class diversity and youth volunteering in the United Kingdom: Applying Bourdieu's Habitus and Cultural Capital. Nonprofit and Voluntary Sector Quarterly, 45(1S), 95S-113S.

Dearing Report. (1997). Higher Education in the Learning Society. London: Her Majesty's Stationary Office.

Dept for Business, Innovation and Skills. (2011). Students at the Heart of the System. In Dept for Business. London: Innovation and Skills.

DfES. (2003). The Future of Higher Education. London: Department for Education and Skills.

Fox, S. (2014). Is it time to update the definition of political participation? Parliamentary Affairs, 67(2), 495505 .

Gaby, S. (2017). The civic engagement gap(s): Youth participation and inequality from $1976-2009$ '. Youth Society, 49(7), 923-946.

Hodkinson, P., \& Sparkes, A. C. (1997). Careership: A sociological theory of career decision making. British Journal of Sociology of Education, 18(1), 29-44.

McIntosh, H., Hart, D., \& Youniss, J. (2007). The influence of family political discussion on youth civic development: Which parent qualities matter? Political Science and Politics. Vol., 40(3), 495-499.

Moore, W. G. (1968). The Tutorial System and Its Future. Oxford: Pergamon Press.

Morgan, M. (2013). Supporting Student Diversity in Higher Education: A Practical Guide. Abingdon.

Nie, N. H., et al. (1996). Education and democratic citizenship in America. London: University of Chicago Press.

Nussbaum, M. (1997). Cultivating Humanity. London: Harvard University Press.

Nussbaum, M. (2010). Not for Profit. Why Democracy Needs the Humanities. New Jersey Princeton University Press.

Putnam, R. D. (2000). Bowling alone: The collapse and revival of American community. New York: Touchstone Books/Simon \& Schuster.

Rees, G., Fevre, R., Furlong, J., \& Gorard, S. (1997). History, place and the learning society: Towards a sociology of lifetime learning. Journal of Education Policy, 12(6), 485-497.

Robbins. (1963). Higher Education: Report of the Committee appointed by the Prime Minister under the Chairmanship of Lord Robbins. London: Her Majesty's Stationary Office.

Rosenstone, S. and Hansen, J. M. 1993. Mobilization, participation and democracy in America.

Schlozman, K. L., Verba, S., \& Brady, H. E. (1999). Civic participation and the equality problem (Vol. 528). Washington: Brookings Institution Press.

Sondheimer, R. M., \& Green, D. P. (2010). Using experiments to estimate the effects of education on voter turnout. American Journal of Political Science, 54(1), 174-189.

Telling, K. (2018). Selling the liberal arts degree in England: Unique students, generic skills and mass higher education. Sociology., 52(6), 1290-1306.

Trow, M.A. (2005). Reflections on the transition from elite to mass to universal access: Forms and phases of higher education in modern societies since WWII. In: Forest, J. J. F. and Altbach, P. G. Eds International handbook of higher education. Springer, Pp. 243-280

Verba, S., Schlozman, K. L., \& Brady, H. E. (1995). Voice and Equality: Civic voluntarism in American politics. Cambridge University Press.

Welsh Assembly Government. (2009). For Our Future: The 21 st Century Higher Education Strategy and Plan for Wales. Cardiff, Wales.

Publisher's note Springer Nature remains neutral with regard to jurisdictional claims in published maps and institutional affiliations. 